\title{
Weekly full-dose gemcitabine and single-dose cisplatin with concurrent radiotherapy in patients with locally advanced
} pancreatic cancer

\author{
SP Hong', JY Park', TJ Jeon', S Bang', SW Park', JB Chung', M-S Park', J Seong ${ }^{3}$, WJ Lee ${ }^{4}$ and SY Song*,1,5 \\ 'Division of Gastroenterology, Department of Internal Medicine, Yonsei Institute of Gastroenterology, Yonsei University College of Medicine, Seoul, Korea; \\ ${ }^{2}$ Department of Diagnostic Radiology, Yonsei Institute of Gastroenterology, Yonsei University College of Medicine, Seoul, Korea; ${ }^{3}$ Department of Radiation \\ Oncology, Yonsei Institute of Gastroenterology, Yonsei University College of Medicine, Seoul, Korea; ${ }^{4}$ Department of Surgery, Yonsei Institute of \\ Gastroenterology, Yonsei University College of Medicine, Seoul, Korea; ${ }^{5}$ Brain Korea 21 Project for Medical Science, Yonsei University College of Medicine, \\ Seoul, Korea
}

The aim of this study was to evaluate the efficacy and the toxicity of a full dose of gemcitabine and a single dose of cisplatin with concurrent radiotherapy in patients with locally advanced pancreatic cancer. Forty-one patients with locally advanced pancreatic cancer were enrolled. Patients received gemcitabine $\left(1000 \mathrm{mg} \mathrm{m}^{-2}\right.$ on days I, 8, 15, 29, and 36) and cisplatin (70 $\mathrm{mg} \mathrm{m}^{-2}$ on days I and 29) with concurrent radiotherapy (45 Gy in 25 fractions). Treatment was completed in 38 out of 41 patients (92.7\%). The overall response rate was $24.4 \%$ (two complete and eight partial). Six patients ( $14.6 \%$ ) underwent definite pancreatic resection and four had negative surgical margins. The intention of the treatment analysis showed that the median survival time and median time to tumour progression were 16.7 and 8.9 months. The I- and 2-year survival rates were 63.3 and $27.9 \%$, respectively. Overall survival was significantly longer in the low baseline CA $19-9$ group and therapeutic responders. Toxicities were tolerable and successfully managed by conservative treatments. The therapeutic scheme of a weekly full dose of gemcitabine and a single dose of cisplatin combined with external radiation is effective and might prolong the survival of patients with locally advanced pancreatic cancer.

British Journal of Cancer (2008) 98, 88I-887. doi: I 0.1038/sj.bjc.6604247 www.bjcancer.com

Published online 26 February 2008

(c) 2008 Cancer Research UK

Keywords: pancreatic cancer; gemcitabine; cisplatin; concurrent chemoradiotherapy

Pancreatic cancer is a leading cause of cancer-related mortality in western countries and accounts for approximately 30000 deaths each year in the United States (Jemal et al, 2005). In Korea, pancreatic cancer accounts for the eighth highest cancer incidence and the fifth highest cancer-related mortality (Ministry of Health and Welfare Republic of Korea, 2007). Surgical resection is the only potentially curative therapy, but only $10-20 \%$ of patients qualify for the procedure (Kalser et al, 1985). The invasion of pancreatic cancer into the major vessels is the main reason why resections cannot be performed. Approximately $30 \%$ of patients are diagnosed with locally advanced disease at initial presentation (Moertel et al, 1981). In this group of patients, there are several reports of favourable results with concurrent chemoradiotherapy.

Gastrointestinal Tumor Study Group $(1979,1988)$ (GITSG) trials demonstrated a survival benefit for patients with locally advanced pancreatic cancer who were treated by external beam radiotherapy and 5-fluorouracil (5-FU) compared with patients who were treated by radiotherapy alone (Moertel et al, 1981). In recent

\footnotetext{
* Correspondence: Dr SY Song, Department of Internal Medicine, Yonsei University College of Medicine, 134 Shinchon-Dong, Seodaemun-Ku, Seoul 120-752, Korea; E-mail: sysong@yuhs.ac

Received 22 May 2007; revised 7 January 2008; accepted 15 January 2008; published online 26 February 2008
}

decades, 5-FU has been considered the standard cytotoxic agent and radiosensitiser for use with concurrent radiotherapy. Since 1996, gemcitabine, a pyrimidine analogue and potent radiosensitiser, has been studied as a substitute for 5-FU in treatments using concurrent chemoradiotherapy (Blackstock et al, 1999; McGinn et al, 2001). Recent phases I and II studies on gemcitabine-based chemoradiotherapy were feasible and improved therapeutic response and survival (Blackstock et al, 1999; McGinn et al, 2001; Okusaka et al, 2004; Magnino et al, 2005).

Many studies have been performed to increase the objective response rate (ORR) and overall survival (OS) by mixed regimens consisting of gemcitabine with other drugs. The combination of gemcitabine and cisplatin has a synergistic effect in vitro in which gemcitabine can inhibit the DNA repair mechanism after cisplatininduced damage, and cisplatin influences gemcitabine metabolism through the inhibition of ribonucleotide reductase (Peters et al, 1995; Bergman et al, 1996). A recent phase III trial with gemcitabine $\left(1000 \mathrm{mg} \mathrm{m}^{-2}\right)$ and cisplatin $\left(50 \mathrm{mg} \mathrm{m}^{-2}\right)$ on days 1 and 15 of a 4 -week cycle showed favourable median OS and median time to tumour progression (TTP) compared with gemcitabine alone in advanced pancreatic cancer (Heinemann et al, 2006). We recently reported the feasibility and clinical efficacy of cisplatin combined with weekly gemcitabine treatments for patients with metastatic pancreatic cancer (Bang et al, 2006b). 
In the present study, we evaluated the efficacy and toxicity of concurrent chemoradiotherapy with a full dose of gemcitabine and a single dose of cisplatin in patients with locally advanced pancreatic cancer. The primary end point of this study was the survival rate, whereas the secondary end points were ORR, TTP, and side effects.

\section{MATERIALS AND METHODS}

\section{Eligibility criteria}

Patients were recruited from January 2000 to December 2005 at the Center for Gastrointestinal Diseases at Severance Hospital in Seoul, Korea. Seven inclusion criteria were used for enrollment: (1) patients must have a newly diagnosed and pathologically confirmed locally advanced pancreatic adenocarcinoma. We defined this cancer stage as when the tumour encases the superior mesenteric arteries or coeliac axis, or occludes the superior mesenteric-portal vein confluence. In these cases, we found no evidence of distant metastatic diseases based on physical examination and radiographic imaging, including positron emission tomography (PET) scans. The tumours were staged according to the American Joint Committee on Cancer (AJCC) staging system (6th edition). (2) Patients must be between the ages of $18-75$ years. (3) Patients must also have an Eastern Cooperative Oncology Group (ECOG) performance status of $0-2 ;(4)$ adequate bone marrow function (white blood cell count $\geqslant 4000 \mathrm{~mm}^{-3}$, absolute neutrophil count $\geqslant 1500 \mathrm{~mm}^{-3}$, haemoglobin $\geqslant 10 \mathrm{~g}$ per $100 \mathrm{ml}$, and platelet count $\geqslant 100000 \mathrm{~mm}^{-3}$ ); (5) adequate hepatic function (alanine transaminase or aspartate transaminase levels $<5$ times the upper limit of institutional normal and bilirubin levels $<3 \mathrm{mg}$ per $100 \mathrm{ml}$ with adequate biliary decompression); (6) adequate renal function (serum creatinine $<2 \mathrm{mg}$ per $100 \mathrm{ml}$ ); and (7) adequate cardiopulmonary function. Patients were ineligible if they had a concurrent type of malignancy, experienced recent upper gastrointestinal bleeding, or any other underlying serious medical conditions that would interfere with the study. This study was approved by the Institutional Review Board of Severance Hospital. We fully informed all patients about the nature and purpose of the study and all patients gave written informed consent.

\section{Treatment plan}

The protocol consisted of a 5-week course of external radiotherapy and concurrent chemotherapy with gemcitabine and cisplatin. Chemotherapy began on the 1st day of radiotherapy: $1000 \mathrm{mg} \mathrm{m}^{-2}$ of gemcitabine was delivered intravenously for $30 \mathrm{~min}$ on days 1,8 , 15 , 29, and 36 , while $70 \mathrm{mg} \mathrm{m}^{-2}$ of cisplatin was delivered intravenously for $2 \mathrm{~h}$ on days 1 and 29. Radiotherapy was administered by linear accelerator (CLINAC 2100C; Varian Medical Systems, Palo Alto, CA, USA) using three-dimensional conformal technique. A total radiation dose of $45 \mathrm{~Gy}$ was delivered with daily doses of $180 \mathrm{cGy}$ for five fractions each week. Gross target volume (GTV) was confined to primary tumour and any regional lymph nodes over $10 \mathrm{~mm}$ detected by computed tomography (CT). Clinical target volume (CTV) was defined as GTV plus primary echelon lymph node according to tumour location. Planning target volume was defined as CTV plus $0.5 \mathrm{~cm}$ margin to cover organ motion and daily set-up error. The four parallel opposing fields (anterior, posterior, and opposed lateral fields) were used, and the radiation dose to the adjacent organs was limited as follows: liver $\leqslant 30 \mathrm{~Gy}$, kidneys $\leqslant 20 \mathrm{~Gy}$, and spinal cord $\leqslant 45 \mathrm{~Gy}$ ).

\section{Response assessments and maintenance therapy}

The primary end point of this study was survival rate, and the secondary end points were ORR (complete response (CR) + partial response (PR)), TTP, and side effects. All patients underwent a pretreatment evaluation consisting of medical history, physical examination, laboratory tests including serum carbohydrate antigen (CA) 19-9, chest X-rays, and high-resolution pancreatic CT scans. These tests were performed within 2 weeks before the start of treatment. Positron emission tomography scans were performed to exclude distant metastases. Endoscopic retrograde cholangiopancreatography and biliary drainage procedures were performed if necessary.

Four weeks after completion of radiotherapy, therapeutic responses were evaluated according to the World Health Organization (WHO) criteria by using chest X-rays and helical CT scans (World Health Organization, 1979). A CR was defined as the disappearance of all measurable or evaluable diseases for a minimum of 4 weeks. Partial response was defined as a $>50 \%$ reduction in the sum of the products of the perpendicular diameters of all measurable lesions for at least 4 weeks. SD was defined as a $<50 \%$ reduction or a $<25 \%$ increase in the sum of the products of the two perpendicular diameters of all measured lesions. Progressive disease (PD) was defined as a $>25 \%$ increase in the sum of the products of the two perpendicular diameters of all lesions or the appearance of any new malignant disease. Patients who did not receive objective evaluations were regarded as PD. If the residual tumours became resectable after chemoradiotherapy, radical resections were performed. Patients with unresectable tumours received maintenance chemotherapy, which was gemcitabine ( $1000 \mathrm{mg} \mathrm{m}^{-2}$ weekly followed by 1 week of rest) and cisplatin ( $75 \mathrm{mg} \mathrm{m}^{-2}$ on day 1 , every 4 weeks). Treatment with gemcitabine and cisplatin continued until there was evidence of disease progression or significant clinical deterioration. Follow-up evaluations were performed every third cycle. Time to tumour progression was calculated from the time of entry into the study until disease progression, and OS was calculated from study entry to death or the last follow-up visit.

\section{Toxicity and dose adjustment}

During chemoradiotherapy, all patients visited the clinic every week and had blood samples taken every 2 weeks for toxicity evaluations. Toxicity was evaluated according to the National Cancer Institute Common Toxicity Criteria (NCI-CTC) version 3.0. The gemcitabine and cisplatin doses were reduced for toxicity on the day of treatment as follows: $75 \%$ of the drug dosage was given to patients with an absolute neutrophil count of $500-900 \mathrm{~mm}^{-3}$ or with a platelet count of $50000-74000 \mathrm{~mm}^{-3}$, and doses were reduced $50 \%$ if patients had an absolute neutrophil count of less than $500 \mathrm{~mm}^{-3}$ or a platelet count of $50000 \mathrm{~mm}^{-3}$. For patients with WHO grades 3-4 nonhaematological toxicity (excluding nephrotoxicity), doses were reduced $75 \%$ for those with grade 3 nonhaematological toxicity (except nausea/vomiting and alopecia) and $50 \%$ for those with grade 4 nonhaematologic toxicity (except nausea/vomiting and alopecia). Radiation therapy was stopped when patients experienced grades 3-4 gastrointestinal toxicities or grade 4 haematological toxicities. Treatments were completely stopped after a second interruption caused by haematological toxicity.

\section{Statistical analysis}

Objective responses were reported according to an intention-totreat basis. On the basis of the most conservative assumption of a $30 \%$ survival rate at 1 year (null hypothesis) in historic controls with locally advanced pancreatic cancer (Okusaka et al, 2004), an increase of $50 \%$ or more (alternative hypothesis) could be shown with a power of $80 \%$ by investigating a sample size of at least 35 patients $(\alpha=0.05$, one-sided test) (A'Hern, 2001). Overall survival and TTP were analysed using Kaplan-Meier method with $95 \%$ confidence intervals (CIs). The univariate analysis to identify 
parameters predicting survival was performed by computing survival curves using Kaplan-Meier method. A $P$-value of less than 0.05 was considered to be statistically significant. When using CA19-9 levels to predict survival, we excluded patients with serum bilirubin levels that were higher than $3 \mathrm{mg}$ per $100 \mathrm{ml}$ at the time when CA19-9 measurements were taken. All statistical analyses were performed with commercially available software (SPSS version 13.0; SPSS Inc., Chicago, IL, USA).

\section{RESULTS}

\section{Patient characteristics}

From January 2000 to December 2005, 41 patients were enrolled in the study. The baseline characteristics of patients are summarised in Table 1 . The patient group had 22 men and 19 women with a median age of 59 years (range: 37-72 years). Fifteen patients $(36.6 \%)$ showed obstructive jaundice at diagnosis and their median serum bilirubin level was $7.0 \mathrm{mg}$ per $100 \mathrm{ml}$ (range: $2.5-24.3 \mathrm{mg}$ per $100 \mathrm{ml}$ ). Endoscopic biliary drainage with a plastic stent was performed on 13 patients while percutaneous biliary drainage was performed on 2 patients. Thirty-three patients $(80.5 \%)$ had elevated CA19-9 levels ( $>37 \mathrm{U} \mathrm{ml}^{-1}$ ) upon initial diagnosis with the median CA19-9 level at $686 \mathrm{U} \mathrm{ml}^{-1}$ (range: $51-20000 \mathrm{U} \mathrm{ml}^{-1}$ ). The median follow-up period was 15.6 months (range: 5.5-52.4 months).

\section{Objective responses, TTP, and OS}

Of the 41 patients, $38(92.7 \%)$ received scheduled chemoradiotherapy. Two patients could not complete the treatment schedule due

Table I Patient characteristics

\begin{tabular}{|c|c|}
\hline Variable & No. of patients (\%) \\
\hline Enrolled patients & 41 \\
\hline \multicolumn{2}{|l|}{ Age (years) } \\
\hline Median (range) & $59(37-72)$ \\
\hline \multicolumn{2}{|l|}{ Sex } \\
\hline Male & $22(53.7)$ \\
\hline Female & $19(46.3)$ \\
\hline \multicolumn{2}{|l|}{ Performance status } \\
\hline ECOG, $0-1$ & $23(56.1)$ \\
\hline ECOG, 2 & $18(43.9)$ \\
\hline Diabetes mellitus & $13(31.7)$ \\
\hline \multicolumn{2}{|l|}{ Symptoms at baseline } \\
\hline Abdominal pain & $31(75.6)$ \\
\hline Jaundice & $15(36.6)$ \\
\hline Weight loss & $22(53.7)$ \\
\hline \multicolumn{2}{|l|}{ Tumour site } \\
\hline Head & $26(63.4)$ \\
\hline Body & $12(29.3)$ \\
\hline Tail & $3(7.3)$ \\
\hline \multicolumn{2}{|c|}{ Tumour size (longest diameter, $\mathrm{cm}$ ) } \\
\hline Median (range) & $3.2(1.5-9.0)$ \\
\hline \multicolumn{2}{|l|}{ Tumour stage } \\
\hline$\| A$ & $8(19.5)$ \\
\hline$\| B$ & $3(7.3)$ \\
\hline III & $30(73.2)$ \\
\hline $\begin{array}{l}\text { CA 19-9 }\left(\mathrm{Um}^{-1}\right) \text { increased } \\
\text { Median (range) }\end{array}$ & $\begin{array}{l}33(80.5) \\
686(5 \mid-20000)\end{array}$ \\
\hline
\end{tabular}

ECOG $=$ Easter Cooperative Oncology Group. to poor general conditions and one patient due to liver abscess. In all, 40 out of the 41 enrolled patients $(97.6 \%)$ received an objective response evaluation and 1 patient was unable to be evaluated for response due to withdrawal from treatment before re-evaluation. This patient was considered to have PD.

Responses were analysed on an intention-to-treat basis. The ORR was $24.4 \%$ while CR and PR were achieved in two patients $(4.9 \%)$ and eight patients (19.5\%), respectively. Twenty-six patients $(63.4 \%)$ and five patients $(12.2 \%)$ showed SD and PD, respectively. Among the four out of five patients who can be evaluated for PD, two had lung metastasis and 2 had metastasis to the liver and multiple lymph nodes. When considering only the primary pancreas tumours, two patients had PR, and two patients had SD. Among the 20 patients who could be evaluated for serum CA19-9 levels, 4 (20\%) had normalised CA19-9 levels and $12(60 \%)$ achieved more than a $25 \%$ reduction in CA19-9 levels after chemoradiotherapy. After completion of chemoradiotherapy, six patients (14.6\%) underwent surgery, four had R0 resections (margin negative), and two had $\mathrm{R} 1$ resections with positive margins. In all, $25(83.3 \%)$ out of 30 patients without surgery received maintenance chemotherapy with a median of 3 cycles (range: $1-9$ cycles).

The median survival time of the 41 enrolled patients was 16.7 months (95\% CI: 10.4-23.1 months) (Figure 1A). The median OS
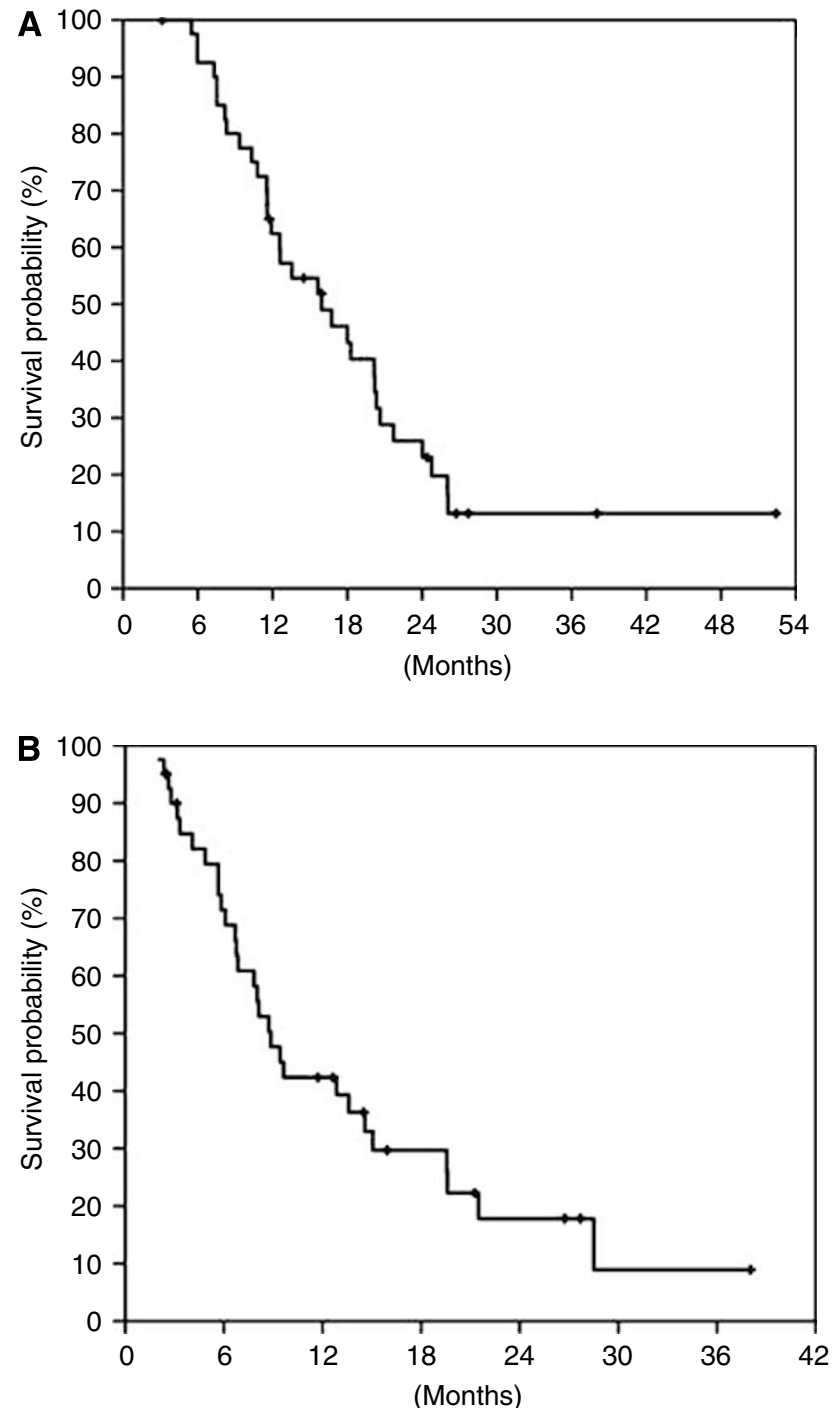

Figure I Overall survival $(\mathbf{A})$ and TTP $(\mathbf{B})$ of the enrolled 4 I patients. 
Table 2 Parameters influencing cumulative survival of patients analysed by univariate analysis

\begin{tabular}{|c|c|c|c|}
\hline Parameters & $\begin{array}{l}\text { Median survival } \\
\text { time (months) }\end{array}$ & $\begin{array}{l}95 \% \mathrm{Cl} \\
\text { (months) }\end{array}$ & $P$-value \\
\hline \multicolumn{3}{|l|}{ Age } & \multirow[t]{3}{*}{0.572} \\
\hline$<60$ & 15.6 & $8.6-22.7$ & \\
\hline$\geqslant 60$ & 16.7 & $8.0-25.5$ & \\
\hline \multicolumn{3}{|l|}{ Sex } & \multirow[t]{3}{*}{0.167} \\
\hline Male & 20.6 & $10.3-31.0$ & \\
\hline Female & 12.6 & $4.2-21.0$ & \\
\hline \multicolumn{3}{|l|}{ Performance status } & \multirow[t]{3}{*}{0.002} \\
\hline ECOG, $0-1$ & 20.1 & $16.8-23.4$ & \\
\hline $\mathrm{ECOG}, 2$ & 10.8 & $6.0-15.5$ & \\
\hline \multicolumn{3}{|l|}{ Weight loss, baseline } & \multirow[t]{5}{*}{0.022} \\
\hline None & 20.3 & $16.2-24.5$ & \\
\hline $\mathrm{I}-5 \mathrm{~kg}$ & 16.7 & $1.6-31.8$ & \\
\hline $6-10 \mathrm{~kg}$ & 12.6 & $5.4-19.7$ & \\
\hline$>10 \mathrm{~kg}$ & 6.0 & $0-13.8$ & \\
\hline \multicolumn{3}{|l|}{ Tumour site } & \multirow[t]{3}{*}{0.152} \\
\hline Head & 20.2 & $13.8-26.7$ & \\
\hline Body-tail & 11.9 & $8.1-15.7$ & \\
\hline \multicolumn{4}{|l|}{ Tumour size } \\
\hline$\geqslant 5 \mathrm{~cm}$ & 20.1 & $0.7-39.6$ & \multirow[t]{2}{*}{0.137} \\
\hline$<5 \mathrm{~cm}$ & 15.9 & $10.7-21.2$ & \\
\hline \multicolumn{3}{|l|}{ T stage } & \multirow[t]{3}{*}{0.556} \\
\hline T3 & 18.3 & $7.8-28.7$ & \\
\hline T4 & 15.9 & $10.9-21.0$ & \\
\hline \multicolumn{3}{|l|}{$N$ stage } & \multirow[t]{3}{*}{0.992} \\
\hline $\mathrm{NI}$ & 15.6 & $6.1-25.2$ & \\
\hline NO & 16.7 & $10.1-23.3$ & \\
\hline & \multirow[t]{3}{*}{0.004} \\
\hline$<1000 \mathrm{Uml}^{-1}$ & 20.1 & $|6.2-24|$. & \\
\hline & 8.2 & $6.3-10.0$ & \\
\hline \multicolumn{3}{|l|}{ Objective response } & \multirow[t]{4}{*}{0.019} \\
\hline$C R+P R$ & 18.3 & $6.2-30.3$ & \\
\hline SD & 16.7 & |3.4-20.| | | & \\
\hline PD & 7.5 & $5.9-9.2$ & \\
\hline \multicolumn{3}{|l|}{ Surgery } & \multirow[t]{3}{*}{0.079} \\
\hline Yes & 21.7 & $14.1-29.3$ & \\
\hline No & 12.6 & $7.5-17.7$ & \\
\hline
\end{tabular}

$\mathrm{CR}=$ complete response; $\mathrm{ECOG}=$ Easter Cooperative Oncology Group; $\mathrm{PD}=$ progressive disease; $\mathrm{PR}=$ partial response; $\mathrm{SD}=$ stable disease.

of resected and unresected patients was 21.7 months (95\% CI: 14.1 - 29.3 months) and 12.6 months (95\% CI: 7.5-17.7 months), respectively $(P=0.079)$. The 1 - and 2 -year cumulative survival rates were 63.3 and $27.9 \%$, respectively. The median TTP was 8.9 months (95\% CI: 7.0-10.7 months) (Figure 1B).

\section{Survival predictor}

The prognostic factors influencing the patients' cumulative survival were analysed (Table 2). Univariate analysis revealed four significant predictors of survival: performance status $(P=0.002)$, baseline weight loss $(P=0.022)$, baseline serum CA19-9 levels $(P=0.004)$, and objective therapeutic response $(P=0.019)$ (Figure 2).
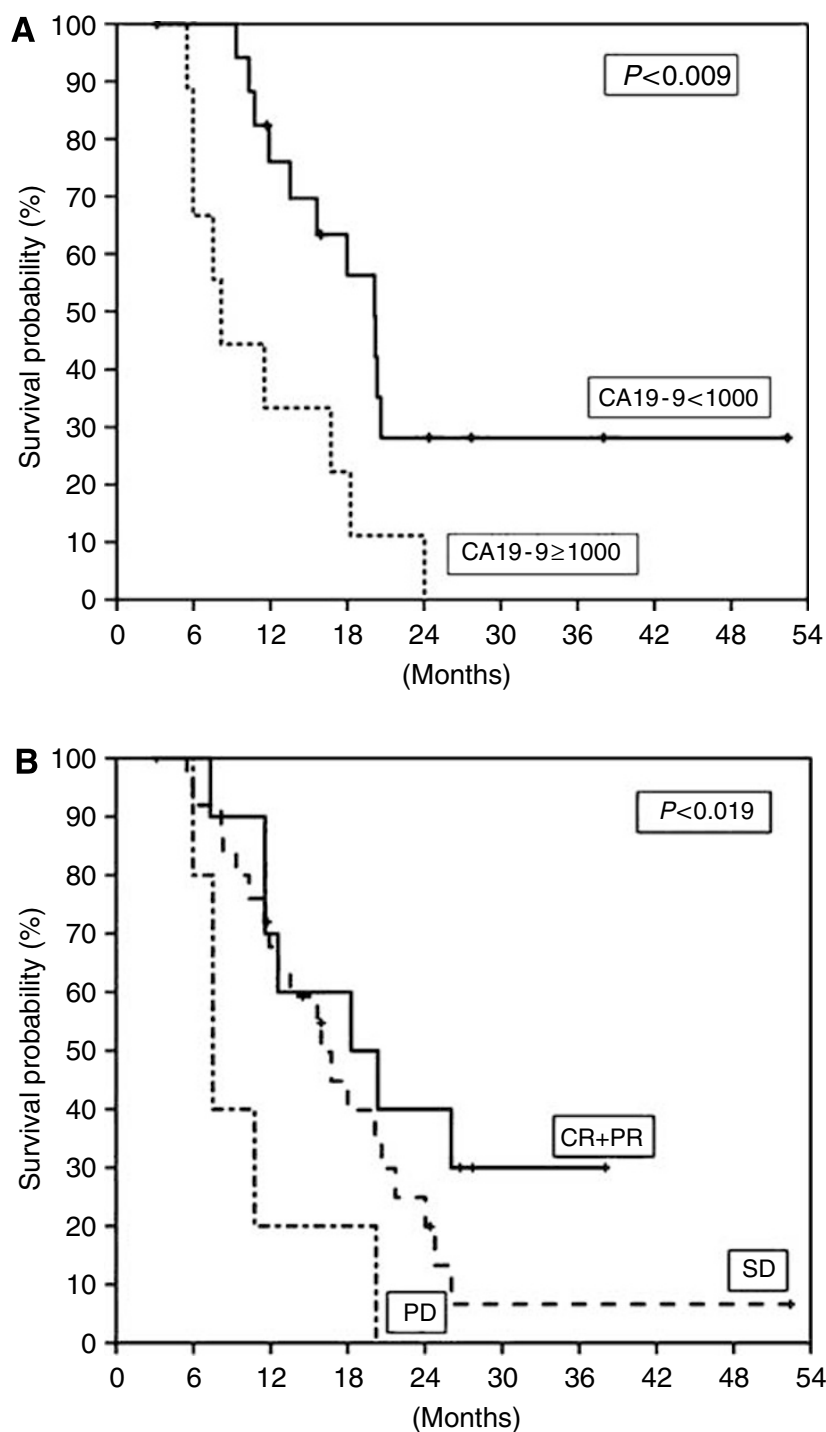

Figure 2 Cumulative survival of patients based on baseline CA I9-9 level (A) and objective response (B). The median survival time of patients with baseline CA19-9 level less than $1000 \mathrm{U} \mathrm{ml}^{-1}$ and more than $1000 \mathrm{U} \mathrm{ml}^{-1}$ were 20.1 and 8.2 months, respectively. The median survival time of patients with objective response (CR+PR), SD, and PD were I8.3, I6.7, and 7.5 months, respectively.

\section{Toxicity}

All 41 patients enrolled in the study were assessed for toxicity. Grades 3-4 toxicities included neutropaenia (26.9\%), thrombocytopaenia (19.5\%), nausea/vomiting $(22 \%)$, diarrhoea $(4.9 \%)$, and infection (2.4\%) (Table 3). No treatment-related deaths occurred. Thirty-eight $(92.7 \%)$ patients received full-dose radiotherapy $(45 \mathrm{~Gy})$, and three patients $(7.3 \%)$ received a $75 \%$ reduced dose of gemcitabine and cisplatin due to myelosupression. One patient was hospitalised due to duodenal ulcer bleeding after completion of chemoradiotherapy.

\section{DISCUSSION}

Chemoradiotherapy affects the local control of a main tumour and downstages the primary tumour by reducing the tumour size, nodal involvement, and vascular invasion. Primarily unresectable pancreatic cancer might converge into a resectable tumour after 
chemoradiotherapy, potentially allowing the patient to expect long-term survival after curative resection (Snady et al, 2000; Ammori et al, 2003). In a chemoradiotherapeutic setting, the chemotherapeutic agent should be a potent radiosensitiser to maximise the therapeutic gain of radiotherapy on primary tumours and have a systemic cytotoxicity to reduce the early metastasis of pancreatic cancer (Moertel et al, 1981; Blackstock et al, 1999).

In the present study, we used a combination of gemcitabine and cisplatin with concurrent radiotherapy. Although we found no consensus between administration schedules for gemcitabine with radiation, recent studies have used twice weekly or weekly administrations of gemcitabine for their main therapeutic schedules (Blackstock et al, 1999; McGinn et al, 2001; Okusaka et al, 2004; Magnino et al, 2005). According to the fact that patients with resectable pancreatic cancer developed early recurrence after surgery due to micrometastases and distant early metastases were important cause of treatment failure of chemoradiotherapy in patients with locally advanced pancreatic cancer, we used weekly gemcitabine treatments in our study (Yeo et al, 1997; Paulino and Latona, 2000). This schedule provided a modest local control and systemic cytotoxicity compared with biweekly administration, which was primarily focused on the effect of the radiosensitiser. In addition, we used a full dose of gemcitabine $\left(1000 \mathrm{mg} \mathrm{m}^{-2}\right)$ to maximise systemic cytotoxicity. Although most of the recent phases I and II studies were performed using a submaximal dose of gemcitabine with radiotherapy, a study by McGinn et al (2001) reported that the standard full dose of gemcitabine was acceptable. Our previous experience also showed that radiotherapy with a full dose of gemcitabine was tolerable (Chung et al, 2004).

Table 3 Treatment-related toxicities according to WHO toxicity criteria

\begin{tabular}{llcll}
\hline & \multicolumn{4}{c}{ No. of patients (\%) } \\
\cline { 2 - 5 } Toxicities & Grade I & Grade 2 & Grade 3 & Grade 4 \\
\hline Haematology & & & & \\
$\quad$ Neutropaenia & $9(22.0)$ & $11(26.8)$ & $7(17.1)$ & $4(9.8)$ \\
Anaemia & $12(29.3)$ & $24(58.5)$ & $0(0)$ & $0(0)$ \\
Thrombocytopaenia & $18(43.9)$ & $7(17.1)$ & $8(19.5)$ & $0(0)$ \\
& & & & \\
Nonhaematology & & & & \\
Nausea/vomiting & $7(17.1)$ & $7(17.1)$ & $9(22.0)$ & $0(0)$ \\
Mucositis & $5(12.2)$ & $2(4.9)$ & $0(0)$ & $0(0)$ \\
Diarrhoea & $1(2.4)$ & $2(4.9)$ & $2(4.9)$ & $0(0)$ \\
Gastric ulcer & $0(0)$ & $3(7.3)$ & $0(0)$ & $0(0)$ \\
Duodenal ulcer & $0(0)$ & $2(4.9)$ & $1(2.4)$ & $0(0)$ \\
AST/ALT & $3(7.3)$ & $6(14.6)$ & $0(0)$ & $0(0)$ \\
Neuropathy & $0(0)$ & $1(2.4)$ & $0(0)$ & $0(0)$ \\
Hypersensitivity & $3(7.3)$ & $1(2.4)$ & $0(0)$ & $0(0)$ \\
Infection & $1(2.4)$ & $2(4.9)$ & $1(2.4)$ & $0(0)$ \\
\hline
\end{tabular}

$\mathrm{ALT}=$ alanine transaminase; $\mathrm{AST}=$ aspartate transaminase
Many attempts have been made to increase the ORR and OS by exploring the combination of gemcitabine with other chemotherapeutic agents. In this study, we used a single dose of cisplatin combined with gemcitabine. There is a report that median TTP and ORR were significantly improved with combined chemotherapy of gemcitabine and cisplatin in patients with locally advanced and metastatic pancreatic cancer (Colucci et al, 2002; Heinemann et al, 2006). Recent phases I and II trials of chemoradiotherapy with a combination of gemcitabine and cisplatin in locally advanced pancreatic cancer patients used a divided dose of cisplatin (Brunner et al, 2003; Wilkowski et al, 2004; Haddock et al, 2007). However, in a study by Shepherd et al, cisplatin was administered in a single dose over a 4-week cycle, and therapeutic effect was superior over divided dose administrations in patients with non-small cell lung cancer.

Previous phases I and II studies were performed with radiotherapy doses of $42-50.4 \mathrm{~Gy}$ and sometimes used boosting doses to achieve local control (Blackstock et al, 1999; McGinn et al, 2001; Brunner et al, 2003; Okusaka et al, 2004; Magnino et al, 2005). In the present study, we used radiation doses of $45 \mathrm{~Gy}$ with 25 fractions. Although four out of five patients with PD who could be evaluated had metastatic disease, two had PR and two had SD of the primary tumour after chemoradiotherapy. Our therapeutic schedule and regimen showed good local control and demonstrated that the treatment failure by concurrent chemoradiotherapy on locally advanced pancreatic cancer was caused not by local progression but early metastasis. These results are consistent with a previous study (Paulino and Latona, 2000).

We summarised recent phase II trials on chemoradiotherapy combined with gemcitabine alone or gemcitabine plus cisplatin in locally advanced pancreatic cancer (Table 4) (de Lange et al, 2002; Li et al, 2003; Okusaka et al, 2004; Wilkowski et al, 2004; Magnino et al, 2005; Haddock et al, 2007). Compared with the recent phase II study by Haddock et al, although the dose and cycle differed from our study, $24.4 \%$ ORR and 16.7 months median survival time of our study showed favourable results.

The major grades 3 and 4 toxicities were haematologic and gastrointestinal toxicities when gemcitabine was combined with radiotherapy. Rates of grades 3 and 4 toxicity in the present study were similar to other reports of gemcitabine-based chemoradiotherapy (Blackstock et al, 1999; McGinn et al, 2001; Brunner et al, 2003; Okusaka et al, 2004; Magnino et al, 2005). In the present study, grades 3 and 4 neutropaenia occurred in $26.9 \%$ of patients and was reversible with conservative therapy. Substantial deterioration of general conditions owing to nausea or vomiting was a major gastrointestinal problem during chemoradiotherapy, and two patients did not complete the scheduled radiation due to gastrointestinal toxicity. Some reports showed fatal gastrointestinal toxicity, especially ulceration and bleeding of the duodenum (McGinn et al, 2001; Brunner et al, 2003). We observed one patient (2.4\%) with duodenal ulcer bleeding after completion of chemoradotherapy who was treated conservatively. Five other patients $(12.2 \%)$ with gastric or duodenal ulcer were also successfully

Table 4 Summary of phase II trials of chemoradiotherapy combined with gemcitabine alone or gemcitabine plus cisplatin in locally advanced pancreatic cancer

\begin{tabular}{|c|c|c|c|c|c|c|c|}
\hline Study & $\begin{array}{c}\text { No. of } \\
\text { patients }\end{array}$ & $\begin{array}{l}\text { Chemotherapy } \\
\text { dose }\left(\mathrm{mg} \mathrm{m}^{-2}\right)\end{array}$ & $\begin{array}{l}\text { RT dose } \\
\text { (Gy) }\end{array}$ & $\begin{array}{c}\text { CR+PR } \\
(\%)\end{array}$ & $\begin{array}{l}\text { Median TTP } \\
\text { (months) }\end{array}$ & $\begin{array}{c}\text { Median } \\
\text { OS (months) }\end{array}$ & $\begin{array}{c}\text { I-year } \\
\text { survival (\%) }\end{array}$ \\
\hline de Lange et al (2002) & 24 & G 300 weekly per 3 weeks & 24 & 29.2 & 7 & 10 & - \\
\hline Wilkowski et al (2004) & 47 & G 300, C 30 weekly per 4 weeks & $45-50$ & 68 & 7.8 & 10.7 & - \\
\hline Okusaka et al (2004) & 42 & G 250 weekly per 6 weeks & 50.4 & 21 & 4.4 & 9.5 & 28 \\
\hline Magnino et al (2005) & 23 & G 50, 100 biweekly per 5 weeks & 45 & 22 & - & 14 & - \\
\hline Haddock et al (2007) & 48 & G 30, C 10 biweekly per 3 weeks & 50.4 & 8 & 7.3 & 10.2 & 40.4 \\
\hline
\end{tabular}

$\mathrm{C}=$ cisplatin; $\mathrm{CR}=$ complete response; $\mathrm{G}=$ gemcitabine; $\mathrm{OS}=$ overall survival; $\mathrm{PR}=$ partial response; $\mathrm{RT}=$ radiotherapy; $T \mathrm{~T}=$ time to progression. 
managed. In the setting of chemoradiation, cisplain-induced neuropathy is not a major toxicity (Brunner et al, 2003; Haddock et $a l, 2007)$. We had only one patient $(2.4 \%)$ with grade 2 neuropathy during chemoradiation. During maintenance therapy, grades $1-3$ neuropathy occurred in $12.1 \%$ of patients.

In the present study, we demonstrated that performance status, baseline weight loss, baseline serum CA19-9 level, and objective therapeutic response were significant predictors of survival by univariate analysis. A recent study by Ferrone et al (2006) reported that preoperative CA19-9 levels could be used as predictors of survival in patients with resectable pancreatic cancer. Their work showed that the cutoff level of $1000 \mathrm{U} \mathrm{ml}^{-1}$ had a strong correlation with survival (Ferrone et al, 2006). We showed that patients with less than $1000 \mathrm{U} \mathrm{ml}^{-1}$ of baseline serum CA19-9 level were longterm survivors.

We performed PET scanning to evaluate distant metastasis in all enrolled patients. Our previous report demonstrated that initial stages using CT scan were changed in $26.9 \%$ patients with pancreatic cancer after PET scan (Bang et al, 2006a). Positron emission tomography scans showed high sensitivity and specificity in detecting metastatic disease, including liver, lungs, and peritoneum (Pakzad et al, 2006; Bang et al, 2006a). Initial staging workup, including PET scans, might be beneficial in selecting good candidates for chemoradiotherapy in locally advanced pancreatic cancer.

This study has a limitation of precise evaluation of resectability of primary pancreatic cancer after chemoradiotherapy. Computed tomography scans make it difficult to differentiate remnant tumours with radiation-induced change in re-staging after chemoradiotherapy. A previous study showed that SD re-staged by CT scan revealed pathological PR after laparotomy (Mornex et al, 2006).

In conclusion, we demonstrated the clinical efficacy and tolerability of treating locally advanced pancreatic cancer with a weekly full dose of gemcitabine and a single dose of cisplatin with concurrent radiotherapy. Combining chemotherapeutic agents are important to achieve not only local control but also good systemic cytotoxicity in patients with locally advanced pancreatic cancer.

\section{REFERENCES}

A'Hern RP (2001) Sample size tables for exact single-stage phase II designs. Stat Med 20: $859-866$

Ammori JB, Colletti LM, Zalupski MM, Eckhauser FE, Greenson JK, Dimick J, Lawrence TS, McGinn CJ (2003) Surgical resection following radiation therapy with concurrent gemcitabine in patients with previously unresectable adenocarcinoma of the pancreas. J Gastrointest Surg 7: $766-772$

Bang S, Chung HW, Park SW, Chung JB, Yun M, Lee JD, Song SY (2006a) The clinical usefulness of 18-fluorodeoxyglucose positron emission tomography in the differential diagnosis, staging, and response evaluation after concurrent chemoradiotherapy for pancreatic cancer. J Clin Gastroenterol 40: 923-929

Bang S, Jeon TJ, Kim MH, Park JY, Park SW, Chung JB, Song SY (2006b) Phase II study of cisplatin combined with weekly gemcitabine in the treatment of patients with metastatic pancreatic carcinoma. Pancreatology 6: 635-641

Bergman AM, Ruiz van Haperen VW, Veerman G, Kuiper CM, Peters GJ (1996) Synergistic interaction between cisplatin and gemcitabine in vitro. Clin Cancer Res 2: $521-530$

Blackstock AW, Bernard SA, Richards F, Eagle KS, Case LD, Poole ME, Savage PD, Tepper JE (1999) Phase I trial of twice-weekly gemcitabine and concurrent radiation in patients with advanced pancreatic cancer. J Clin Oncol 17: 2208-2212

Brunner TB, Grabenbauer GG, Klein P, Baum U, Papadopoulos T, Bautz W, Hohenberger W, Sauer R (2003) Phase I trial of strictly time-scheduled gemcitabine and cisplatin with concurrent radiotherapy in patients with locally advanced pancreatic cancer. Int J Radiat Oncol Biol Phys 55: $144-153$

Chung HW, Bang SM, Park SW, Chung JB, Kang JK, Kim JW, Seong JS, Lee WJ, Song SY (2004) A prospective randomized study of gemcitabine with doxifluridine versus paclitaxel with doxifluridine in concurrent chemoradiotherapy for locally advanced pancreatic cancer. Int J Radiat Oncol Biol Phys 60: 1494-1501

Colucci G, Giuliani F, Gebbia V, Biglietto M, Rabitti P, Uomo G, Cigolari S, Testa A, Maiello E, Lopez M (2002) Gemcitabine alone or with cisplatin for the treatment of patients with locally advanced and/or metastatic pancreatic carcinoma: a prospective, randomized phase III study of the Gruppo Oncologia dell'Italia Meridionale. Cancer 94: 902-910

de Lange SM, van Groeningen CJ, Meijer OW, Cuesta MA, Langendijk JA, van Riel JM, Pinedo HM, Peters GJ, Meijer S, Slotman BJ, Giaccone G (2002) Gemcitabine-radiotherapy in patients with locally advanced pancreatic cancer. Eur J Cancer 38: 1212-1217

Ferrone CR, Finkelstein DM, Thayer SP, Muzikansky A, FernandezdelCastillo C, Warshaw AL (2006) Perioperative CA19-9 levels can predict stage and survival in patients with resectable pancreatic adenocarcinoma. J Clin Oncol 24: 2897-2902

Gastrointestinal Tumor Study Group (1979) A multi-institutional comparative trial of radiation therapy alone and in combination with 5-fluorouracil for locally unresectable pancreatic carcinoma. Ann Surg 189: $205-208$

Gastrointestinal Tumor Study Group (1988) Treatment of locally unresectable carcinoma of the pancreas: comparison of combined-modality therapy (chemotherapy plus radiotherapy) to chemotherapy alone. J Nat Cancer Inst 80: $751-755$

Haddock MG, Swaminathan R, Foster NR, Hauge MD, Martenson JA, Camoriano JK, Stella PJ, Tenglin RC, Schaefer PL, Moore DF, Alberts SR (2007) Gemcitabine, cisplatin, and radiotherapy for patients with locally advanced pancreatic adenocarcinoma: results of the North central cancer treatment group phase II study N9942. J Clin Oncol 25: 2567-2572

Heinemann V, Quietzsch D, Gieseler F, Gonnermann M, Schönekäs H, Rost A, Neuhaus H, Haag C, Clemens M, Heinrich B, Vehling-Kaiser U, Fuchs M, Fleckenstein D, Gesierich W, Uthgenannt D, Einsele H, Holstege A, Hinke A, Schalhorn A, Wilkowski R (2006) Randomized phase III trial of gemcitabine plus cisplatin compared with gemcitabine alone in advanced pancreatic cancer. J Clin Oncol 24: 3946-3952

Jemal A, Murray T, Ward E, Samuels A, Tiwari RC, Ghafoor A, Feuer EJ, Thun MJ (2005) Cancer statistics, 2005. CA Cancer J Clin 55: 10-30

Kalser MH, Barkin J, MacIntyre JM (1985) Pancreatic cancer. Assessment of prognosis by clinical presentation. Cancer 56: 397-402

Li CP, Chao Y, Chi KH, Chan WK, Teng HC, Lee RC, Chang FY, Lee SD, Yen SH (2003) Concurrent chemoradiotherapy treatment of locally advanced pancreatic cancer: gemcitabine versus 5-fluorouracil, a randomized controlled study. Int J Radiat Oncol Biol Phys 57: 98 - 104

Magnino A, Gatti M, Massucco P, Sperti E, Faggiuolo R, Regge D, Capussotti L, Gabriele P, Aglietta M (2005) Phase II trial of primary radiation therapy and concurrent chemotherapy for patients with locally advanced pancreatic cancer. Oncology 68: 493-499

McGinn CJ, Zalupski MM, Shureiqi I, Robertson JM, Eckhauser FE, Smith DC, Brown D, Hejna G, Strawderman M, Normolle D, Lawrence TS (2001) Phase I trial of radiation dose escalation with concurrent weekly full-dose gemcitabine in patients with advanced pancreatic cancer. J Clin Oncol 19: $4202-4208$

Ministry of Health and Welfare Republic of Korea (2007) Annual report of national cancer registration 1999-2002

Moertel CG, Frytak S, Hahn RG, O’Connell MJ, Reitemeier RJ, Rubin J, Schutt AJ, Weiland LH, Childs DS, Holbrook MA, Lavin PT, Livstone E, Spiro H, Knowlton A, Kalser M, Barkin J, Lessner H, Mann-Kaplan R, Ramming K, Douglas HO, Thomas P, Nave H, Bateman J, Lokich J, Brooks J, Chaffey J, Corson JM, Zamcheck N, Novak JW (1981) Therapy of locally unresectable pancreatic carcinoma: a randomized comparison of high dose (6000 rads) radiation alone, moderate dose radiation (4000 rads +5 -fluorouracil), and high dose radiation +5 -fluorouracil: the gastrointestinal tumor study group. Cancer 48: 1705-1710

Mornex F, Girard N, Scoazec JY, Bossard N, Ychou M, Smith D, Seitz JF, Valette PJ, Roy P, Rouanet P, Ducreux M, Partensky C (2006) Feasibility of preoperative combined radiation therapy and chemotherapy with 
5-fluorouracil and cisplatin in potentially resectable pancreatic adenocarcinoma: the French SFRO-FFCD 97-04 Phase II trial. Int J Radiat Oncol Biol Phys 65: 1471-1478

Okusaka T, Ito Y, Ueno H, Ikeda M, Takezako Y, Morizane C, Kagami Y, Ikeda H (2004) Phase II study of radiotherapy combined with gemcitabine for locally advanced pancreatic cancer. $\mathrm{Br} J$ Cancer 91: 673-677

Pakzad F, Groves AM, Ell PJ (2006) The role of positron emission tomography in the management of pancreatic cancer. Semin Nucl Med 36: $248-256$

Paulino AC, Latona C (2000) Unresectable adenocarcinoma of the pancreas: patterns of failure and treatment results. Cancer Invest 18: 309-313

Peters GJ, Bergman AM, Ruiz van Haperen VW, Veerman G, Kuiper CM, Braakhuis BJ (1995) Interaction between cisplatin and gemcitabine in vitro and in vivo. Semin Oncol 22: $72-79$
Snady H, Bruckner H, Cooperman A, Paradiso J, Kiefer L (2000) Survival advantage of combined chemoradiotherapy compared with resection as the initial treatment of patients with regional pancreatic carcinoma. An outcomes trial. Cancer 89: $314-327$

Wilkowski R, Thoma M, Schauer R, Wagner A, Heinemann V (2004) Effect of chemoradiotherapy with gemcitabine and cisplatin on locoregional control in patients with primary inoperable pancreatic cancer. World $J$ Surg 28: $1011-1018$

World Health Organization (1979) WHO Handbook for Reporting Results of Cancer Treatment Offset Publication 48. Geneva: World Health Organization

Yeo CJ, Cameron JL, Sohn TA, Lillemoe KD, Pitt HA, Talamini MA, Hruban RH, Ord SE, Sauter PK, Coleman J, Zahurak ML, Grochow LB, Abrams RA (1997) Six hundred fifty consecutive pancreaticoduodenectomies in the 1990s: pathology, complications, and outcomes. Ann Surg 226: 248 -257; discussion 257 